\title{
Epigenética de la enfermedad renal
}

\author{
Cesar Vásconez ${ }^{1}$
}

Este artículo está bajo una licencia de Creative Commons de tipo Reconocimien-

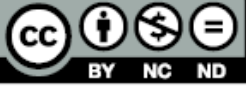

OPEN ACCESS

1 Médico especialista en Nefrología -Diálisis-Trasplante, Magister en Gerenciamiento Hospitalario. Jefe del Servicio de Nefrología Hospital Vozandes.

ORCID ID:

Cesar Vásconez V.

https:/ / orcid.org/0000-0002-3591-5994

Correspondencia: Dr. Cesar Vásconez Vaca.
Para nosotros generar una definición determinada y entendible necesitamos de elementos de comparación; así, por ejemplo, para nosotros "entender "que es el "día" necesariamente debemos conocer que es la "noche". Esta antítesis por contraste nos grafica estos dos conceptos y nos lleva al ámbito de la "certidumbre" y es por esto que un "eclipse total" en pleno día se presenta como un fenómeno de ruptura de lo conocido como "cierto" desde que nacemos y que NO admite contradicción pues es ya parte de nuestra "conciencia genética" ; es decir, un evento externo de la vida real (día-noche) condicionado a eventos internos (genéticos) generando - en el caso del ejemplo - el "ritmo circadiano", "envejecimiento celular", "esperanza de vida al nacer", "cronobiología".

Esta interrelación entre el MEDIO AMBIENTE y nuestra INDIVIDUALIDAD BIOLOGICA y que comúnmente lo llamaremos como "Procesos de ADAPTABILIDAD" en donde el "equipo que traemos de fabrica (genética)" debe ser modulado, dirigido en relación a su entorno para "adaptar" la biología haciendo uso de herramientas que nos enseñen "COMO USAR DE LA MANERA MAS EFICIENTE y EFICAZ" ese EQUIPO que ya lo tenemos para conseguir el cumplimiento de la ESPERANZA de VIDA (codificada genéticamente) y NO quedarnos tan solo en el "deseo" por conseguir efectivamente este propósito, lo que conocemos como EXPECTATIVA DE VIDA.

La Esperanza de Vida NO es VARIABLE, la Expectativa de vida SI es MODIFICABLE; o en otras palabras: la ESPERANZA de VIDA está determinada GENETICAMENTE, mientras que la EXPECTATIVA de VIDA está condicionada EPIGENETICAMENTE.
Visto así, la EPIGENETICA es el DIRECTOR de ORQUESTA y la GENETICA son los MUSICOS con sus instrumentos, que van a ser dirigidos por el MAESTRO con el OBJETIVO de conseguir una EJECUCION BRILLANTE, PERFECTA, que intenta obtener la máxima virtuosidad de cada uno de los intervinientes, haciéndolos actuar en el momento justo dependiendo de la partitura. Por supuesto, la perfección en la ejecución se "apreciará" o mejor "se escuchará" mejor o peor dependiendo del entorno en el cual se ejecute (teatro, ágora......etc.) así como de las "herramientas" (instrumentos) y dependiendo del "oído" educado o no del público. Como vemos $\mathrm{NO}$ es suficiente con SER UN GRAN MUSICO necesitamos un GRAN DIRECTOR.

¿Cómo explicamos el hecho de que un ser tan bello y delicado como es una MARIPOSA provenga de una "oruga"?

El fenómeno de metamorfosis natural se produce SIN NINGUNA MODIFICACION en la SECUENCIA del ADN, ni en su estructura misma (el ADN de la oruga es el mismo que el de la mariposa)

Aquí es donde la EPIGENETICA explica que si bien el material genético se mantiene intacto; son procesos de METILACION O DESMETILACION del ADN y/o de las HISTONAS cuyo objetivo no es cambiar la estructura del ADN sino la de ACTIVAR o DESACTIVAR "genes" en respuesta a........ Y precisamente es este proceso de metilación el que denominaremos como "LA HUELLA EPIGENETICA" es decir lo que nos permite visualizar en CLINICA los efectos del "entorno" sobre las expresiones biológicas de salud o enfermedad (adaptabilidad), siendo este uno de los procesos Epigenéticos (la metilación es la adición de un grupo METLO- CH3- en los islotes CpG de las cadenas de ADN) 
"MIENTRAS MAS METILACION MENOS ACTIVACION GENICA Y VICEVERSA"

Hablando de SALUD RENAL, podemos decir en términos generales que al ser los riñones órganos ENDOTELIALES, se convierten en el "albo" de los procesos inflamatorios y de "autoinmunidad patológica " como respuesta a un sinfín de agresiones que se expresan clínicamente como la Hipertensión Arterial y/o como una pérdida paulatina de las funciones cuyo anuncio precoz es la aparición de proteína en la orina (de hecho es el examen de orina simple en donde podemos corroborar más del $90 \%$ de los diagnósticos de enfermedades renales).

Se visualizan extemporáneamente y con la salvedad de la Enfermedad Renal Poliquística, el Síndrome Nefrótico Infantil (variantes) en donde es clara la evidencia genética, la mayor parte de las afectaciones renales son la consecuencia de una respuesta de defensa comúnmente subclínica y progresiva, por ello podemos presenciar el misMO SINDROME NEFROTICO primario; O secundario a la DIABETES MELLITUS II y también sabemos que el bloqueo de la ANGIOTENSINA (en realidad toda la secuencia Renina-Angiotensina -Aldosterona) genera efectos benéficos en el control y a veces remisión de la proteinuria, demostrada en estudios de animales de laboratorio como una consecuencia de la Hipertensión Intra Glomerular así como de cambios adaptativos en la Membrana Basal Glomerular que la vuelven permeable a las proteínas.

Con la aparición de la EPIGENETICA ahora tenemos conocimiento del mecanismo de activación o desactivación de la vía de la Angiotensina hasta provocar la expresión o no, del gen de la NEFRINA, que puede ser modulado por la acción de fármacos inhibidores de la Angiotensina y así también podemos hablar de otro viejo fármaco, como es la Hidralazina, que también genera un beneficio en el control de la proteinuria al incidir sobre los mecanismos de metilación del ADN o Acetilación de las Histonas; provocando la inhibición o silenciamiento génico como efecto beneficio en el control de la enfermedad renal.

El conocimiento de los ahora denominados SUPER ALIMENTOS, también tienen un efecto EPIGENETICO sobre la Salud Renal, de hecho, una de las principales armas terapéuticas para enlentecer el ritmo de evolución de la enfermedad Renal hacia estadios terminales, son las manipulaciones nutricionales en base a la restricción de la proteína de origen animal. Todo esto, avizora el nuevo campo de la CLINICA mediante intervenciones terapéuticas y nutricionales de carácter EPIGENETICO desactivando genes que propicien la aparición de enfermedades degenerativas y /o crónicas, o activando genes que promuevan la longevidad y la salud biológica limitando, disminuyendo o quizás desapareciendo el uso de medicamentos "químicos "con un sinfín de efectos indeseables, por mucho que ahora nos parezcan indispensables y/o insubstituibles.

Para recordar " Al nacimiento traemos toda la carga de Metilación necesaria para mantener silentes muchos genes inconvenientes y que se irán activando conforme avanza la edad, y, al final de la misma, esta carga se convertirá en un evento de HIPOMETILACION del ADN ; pudiendo propiciar la presencia de las enfermedades degenerativas, neoplásicas, crónicas ; siendo estas la principal causa de mortalidad ahora y al 2040; dentro de las cuales; la Enfermedad Renal Crónica Terminal ocupara el cuarto lugar".

\section{Referencias}

1.Wade N. Una herencia incómoda, genes, raza e historia humana. Segunda Edición: Editora Ariel; 2014.

2.Gonzales H. Tenemos menos genes que un brócoli...y se nota. La esfera de los libros SI; 2017.
3.De la Peña C, Loyola M. De la Genética a la Epigenética. La ciencia para Todos. p. 247

4.Roma C. La Epigenética. CSIC; 2014

5.Carey N. La Revolución Epigenética. ISBN;2013
6.De la Torre M. Introducción a la Epigenética, nuevo Paradigma en la Nefrologia. Sección de Nefrologia. Nefro Plus. 2017;9 (1):1-10 